\title{
Transver o mundo: linguagens criativas de crianças em situação de confinamento
}

Cristiana Callai ${ }^{1}$

Greice Duarte de Brito Silva²

Marta Nidia Varella Gomes Maia ${ }^{3}$

Submetido em: 04/08/2020

Aprovado em: 30/10/2020

DOI: $10.5965 / 23580925242020013$

1 Doutora em Educação. Professora na Universidade Federal Fluminense (UFF). E-mail: criscallai@gmail.com

2 Mestra em Educação. Professora da Educação Básica no Colégio Universitário Geraldo Reis (COLUNI - UFF).

3 Doutora em Educação. Professora da Universidade Federal Fluminense. 


\section{RESUMO}

Estamos vivendo uma crise epidemiológica, o COVID-19, o qual nos impõe o confinamento social. Nesse contexto, nos interessa perceber como as crianças estão habitando a casa. Apresentamos em três sessões, fragmentos de encontros com três crianças, que nos convidam ao olhar sensível que admira, valoriza e potencializa as manifestações infantis nesse espaço-tempo de restrição. Pretendemos dar a ver como as crianças estão interagindo com o mundo a partir de seus quintais: quintais sala, quintais varandas, quintais janelas. Um convite para que possamos olhar para as minúcias da vida cotidiana com as crianças e com elas transver o mundo. Assim, em parceria com autores que falam da arte, da sensibilidade estética, das potencialidades da infância, se constitui esse texto-convite. A pesquisa (auto)biográfica foi assumida como pressuposto metodológico.

Palavras-chave: infância, arte, confinamento social.

\section{ABSTRACT}

We are experiencing an epidemiological crisis, COVID-19, which imposes social confinement on us. In this context, we are interested in seeing how children are living in the house. In three sessions, we present fragments of meetings with three children, which invite us to the sensitive look that admires, values and enhances children's manifestations in this space-time of restriction. We intend to show how children are interacting with the world from their backyards: backyard rooms, backyard yards, backyard windows. An invitation so that we can look at the minutiae of everyday life with children and with them cross the world. Thus, in partnership with authors who speak about art, aesthetic sensitivity, the potential of childhood, this invitation text is constituted. 
The (auto) biographical research was assumed as a methodological assumption.

Keywords: childhood, art, social confinement.

\section{POR UM PENSAR ESTÉTICO}

A vulnerabilidade da vida na crise epidemiológica que assola o mundo exige de nós, professoras/pesquisadoras, um olhar sensível para esse espaço-tempo de confinamento social. Como as crianças estão habitando a casa? A presente questão mobilizou o nosso interesse em observar e registrar o brincar e as brincadeiras de três crianças em isolamento social.

Considerando a pluralidade das experiências sociais vividas neste tempo que singularizam-se nas histórias individuais, optamos pela pesquisa (auto)biográfica no traçado metodológico deste trabalho. Constituída por histórias de vida, relatos orais e fotografias que se configuram como objeto de investigação transversal nas Ciências Sociais e Humanas, segundo as quais os indivíduos - no caso as crianças em situação de confinamento - atuam e incorporam biograficamente os acontecimentos e as experiências de aprendizagem ao longo da vida, como afirma Conceição Passeggi (2018).

No reconhecimento da criança como sujeito da experiência, que ao decidir reconstruir sua realidade, age com o seu pensar, o seu sentir e o seu querer (PASSEGGI, 2018). Criança que produz narrativas com frases curtas e breves como na "história de um instante, história de uma hora, de um dia", na concepção minimalista de biografização (DELORY-MOMBERGER, 2012).

As lentes escolhidas para ampliar e perceber os sentidos das experiências com as crianças vem do diálogo com as artes,

4 Delory Momberger (2012) entende por biografização o caráter processual da atividade biográfica, que remete a todas as operações mentais, comportamentais e verbais pelas quais o indivíduo não cessa de inscrever sua experiência e sua ação em esquemas temporais orientados e finalizados. 
na expansão do conceito de arte no contexto do trabalho educativo entre crianças e adultos (HOLM, 2005). Poéticas infantis que refratam linguagens criativas, através de uma percepção outra, assim como a do poeta Manoel de Barros, a qual nos convida transver o mundo.

\section{A CASA VIROU MUNDO}

E, de repente, de um dia para o outro, nos vemos confinados em casa. A quarentena chegou. O mundo que habitávamos ficou reduzido ao espaço de nossa casa. A casa virou mundo.

Dos tensionamentos desse momento em que estamos ameaçados pelo Coronavírus (COVID-19), se sobressai a preocupação com as crianças que foram apartadas dos espaços públicos, parques, praças, escolas, entre outros. Com o passar dos dias, ressignificamos o espaço da casa organizada, para a casa que vira muitas coisas através do brincar, vira mundo!

O olhar infantil amplia o corriqueiro e o comum, transforma os sentidos dos utensílios, cria mundos nos cantos da casa e evoca as miudezas. O universo particular da criança esgarça o cotidiano, transfigura-o.

A casa vira mundo, nesse lugar, encontramos Manoel de Barros com sua poesia refratada nas brincadeiras das crianças, com o apreço às coisas desimportantes. "Um caneco furado que não carrega água é muito mais importante do que um tanque de água. Isso, claro, pela inutilidade do caneco furado. As coisas desprezadas pela civilização são objetos de poesia. Digo, aliás, que os desobjetos só prestam para a poesia" (BARROS, 2010, p. 110).

Manoel de Barros partilha uma poesia feita de restos, sobras e desperdícios, nos atrai para um intenso movimento de busca que não se completa, uma vez que suas palavras não apontam um ponto de chegada, muito menos nos direciona para um lugar de significados engessados. As crianças evocam essa poesia das miudezas ao habitar a casa de um modo mais intenso. 
Em suas poesias Manoel de Barros desconstrói o saber formal, aqueles contidos nos livros de ciência e acaba nos propondo um outro olhar, acompanhado ao seu. Ele nos atrai para as coisas do chão, para as pequenas coisas. Os restos. As coisas sem importância. Descortina outra ciência, a que estava escondida, talvez, debaixo da pedra ou em cima das árvores, lugares que nossa visão não alcança. Junto a uma criança de 4 anos, alguns registros.

No horizonte, o anúncio do anoitecer.

Entre matizes de azul, a lua desponta.

Ela, com seus dedos pequenos aponta para o céu.

O que vemos?

O sublime de um instante.

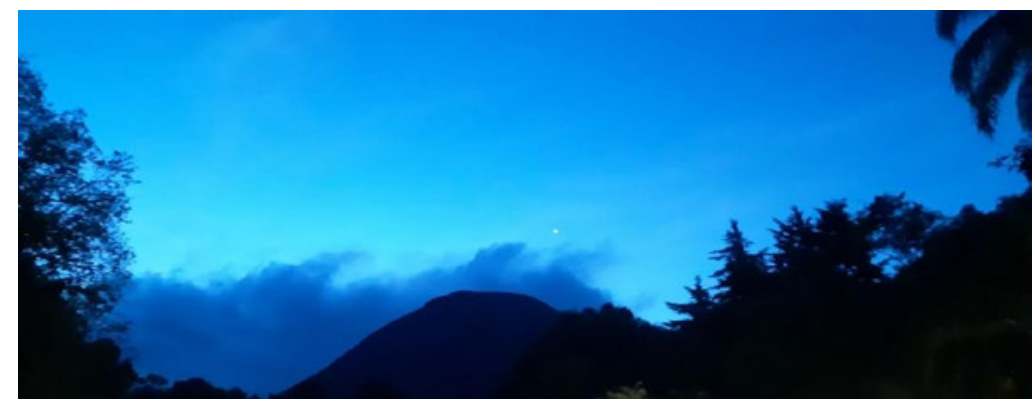

Figura 01

Fonte: arquivo pessoal de Cristiana Callai (junho/2020)

Transvendo o olhar seguimos com as crianças, tão barreanas em suas descobertas de mundo, forçando-nos a olhar para o que não víamos. Nosso olhar acostumado já antecipava os percursos, não parava, olhava, examinava... Olhos que não viam são despertados pelos olhos infantis, curiosos olhos para o ínfimo. Encontramos poesia no desperdício.

A cortina que antes, intocável, enfeitava as portas de vidro, 
agora são esconderijos, abrigam corpos e brinquedos. Na brincadeira, os pequenos detalhes são importantes na composição de cenários, utensílios da casa são reinventados em um fazer inusitado.

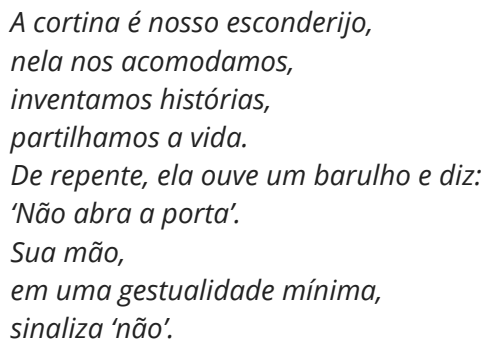

Para Benjamin (1994), as brincadeiras e os jogos infantis são impregnados de comportamentos miméticos que vão além da imitação de pessoas, ultrapassando o que poderia ser entendido como imitação, porque a criança inventa outras relações, nem sempre previstas.

Ao viver o confinamento, a criança se apropria dos signos culturais, internalizando, reproduzindo e reinventando gestos cumprimentar com os cotovelos, modos de andar - respeitando o distanciamento, de falar - usando máscaras, de sentir - não sabendo ao certo o que estão sentindo, de ser - nesse momento de tanta vulnerabilidade.

A literatura assume um papel importante para nos conectarmos com nossos sentimentos. Nas histórias, os pequenos olhos atentos às letras e às imagens, ouvidos aguçados à escuta. A poética da voz que convida a uma viagem. E, assim que a leitura termina, há um sussurro: - Conta de novo!

No contar, dedilho o seu corpo...

Ela experimenta as intensidades da narrativa.

Ora suave, anunciando um dia na floresta;

Outrora, assustador, será lobo ou caçador?

Eu digo: - ela andava pela floresta...

E meus dedos dedilham seus pés subindo até as pernas...

Ela ri e diz: - De novo! 
A importância das histórias infantis para a formação da criança também pode ser percebida pelo desejo apresentado de ouvir várias vezes a mesma narrativa. De acordo com Benjamin (2007, p. 75), para a criança, "não basta duas vezes, mas sim sempre de novo, centenas e milhares de vezes".

Contando histórias, recontamos o mundo e criamos a nossa poesia ao habitar a casa de um outro modo. É em poesia que o mundo se transfigura e faz o verbo delirar. No delírio do verbo, o poeta desnuda a lógica e a razão, somos afetados, ouvimos a cor do passarinho, sem explicação, apenas com afeto.

\section{Folhas, gravetos e sementes... \\ Eis a barreana, \\ Recolhe o desperdício \\ É o tesouro de Manoel \\ Depois coloca tudo no chão \\ E diz: - Vamos brincar?}

Talvez seja por isso que Manoel elege a criança como a primeira personagem que lhe serve como "doadores de fontes" de suas memórias, uma vez que admite, "a criança me deu a semente da palavra" (BARROS, 2008, p.127). Em sua escrita habita a ludicidade, os deslocamentos, as inversões de sentidos, a potência dos neologismos, a inovação. Não é à toa que o próprio poeta em sua poesia confessa: “Eu tenho um ermo enorme dentro do olho. Por motivo do ermo não fui um menino peralta. Agora tenho saudade do que não fui. E com esta sensatez atual me voltou a criancês. Acho que o que faço agora é o que não pude fazer na infância" (BARROS, 2008, p.15).

\section{A DANÇA DO SOL}

As transformações sociais impactam a vida das crianças. Nos últimos anos, criamos espaços infantis, atividades e fazeres apartados da casa e, agora em isolamento social, crianças usufruem de um modo de vida privado. Espera-se que elas con- 
tinuem protegidas. Neste sentido, partem em busca de seus outros aliados, encontrados facilmente no mundo dos fenômenos (BENJAMIN, 2007).

Entre as observações de uma segunda criança de dois anos, o sol que vai e vem, nasce aqui e põe-se acolá, revelou seu espetáculo suntuoso. Sempre esteve ali despercebido. Até que o mundo-casa se tornou um palco de descobertas. Da janela aberta, o que se vê? A dança do sol, diz a criança confinada acompanhada por seus pais.

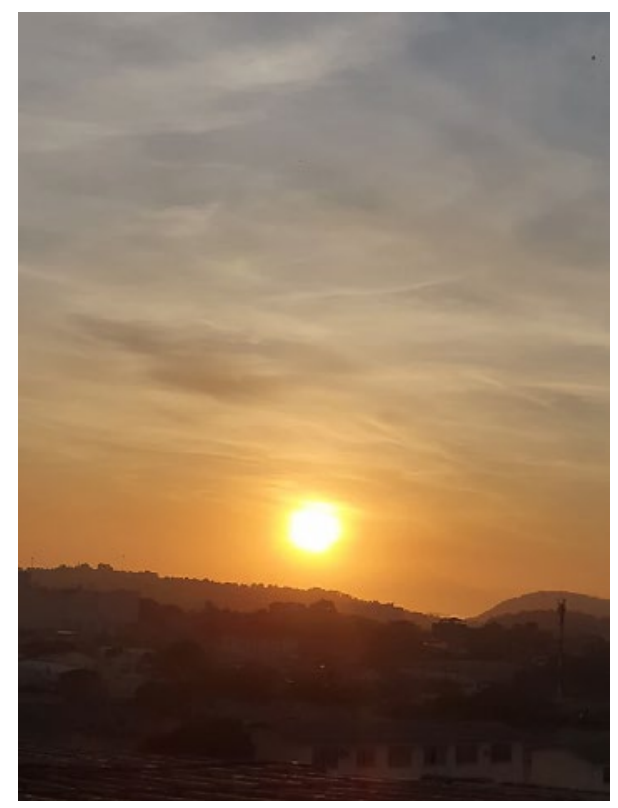

Figura 02

Fonte: arquivo pessoal de Tatiana Siqueira cedida para esse trabalho (maio/2020)

O encontro com crianças é sempre provocador. Na narrativa do livro "Eco-arte com crianças" (2015), a artista dinamarquesa conta como um céu azul escuro, típico das tardes de inverno em 
seu país, atrai a atenção de um menino. A partir de sua tentativa em agarrar o céu, a artista se dá conta que estão juntos ancorados no planeta. Assim, surge um questionamento necessário: como podemos trabalhar com crianças e expressão artística de forma ecológica?

Lembrando que eco vem do termo grego oikos, que pode significar casa. Habitamos todos uma casa que está em crise, por isso estamos em confinamento. Do lar podemos ajudar a manter nossa casa, o planeta. Pensando e fazendo arte, promovendo o equilíbrio e não usando mais do que é necessário (HOLM, 2015).

De acordo com a artista dinamarquesa, na pesquisa artística somos nós quem construímos o espaço, onde atividade artística e brincadeira são partes que se integram. Natureza e arte brincam com as crianças. Ao observar, explorar e experimentar ainda que dentro de casa, fazem-nos reconhecer na simplicidade, na intimidade do cotidiano, possibilidades e questionamentos. Há muitas possibilidades no lugar, nas relações físicas e sensoriais incluídas nas interações entre as crianças, os adultos e o mundo.

Outro ponto interessante: é possível utilizar a energia da própria natureza como ferramenta de um processo criativo. Ao ar livre no quintal ou no pequeno espaço do apartamento somos capazes, junto às crianças, de enredar fazeres criativos. Desde que, de acordo com Holm, possamos reconhecer como um presente a presença do vento, da chuva e do sol. Brincar com esses fenômenos transforma-os em ferramentas artísticas e lúdicas, assim como ser um caçador do sol, faz da criança um protagonista. Simples interações capazes de levá-la a grandes perguntas.

Importante reconhecer que as crianças pequenas possuem outro olhar para as artes, elas não guardam distância dos espetáculos e das obras. Elas querem fazer parte! Para Anna Marie Holm (2015), crianças entendem a arte enquanto ação. Querem encontro, participação e desafios. Nesta perspectiva, o ambiente artístico pode ser qualquer lugar onde haja exploração da interação, e, o sentido está em encontrar algo junto. 
Acerca da necessidade infantil de dialogar com as coisas do mundo real e da imaginação, a pesquisadora Ana Angélica Albano (2018) discorre sobre outros espaços de imaginação. Reconhece que os quintais e os pátios de casa são territórios privilegiados nas recordações da infância. Acredita que justo pelo motivo da intimidade, como diria Manoel de Barros.

Acho que o quintal onde a gente brincou é maior do que a cidade. A gente só descobre isso depois de grande. A gente descobre que o tamanho das coisas há de ser medido pela intimidade que temos com as coisas. Há de ser como acontece com o amor. Assim as pedrinhas do nosso quintal são sempre maiores do que as outras pedras do mundo. Justo pelo motivo da intimidade (BARROS, 2008, s/p).

Sabemos que os desejos das crianças não cabem no tamanho do papel A4. Desta forma, Ana Angélica ajuda a pensar nossa casa-mundo como um ateliê de artes. Como um território privilegiado do respeito à individualidade, da construção da identidade dentro da diversidade, com suas portas abertas para a imaginação. Em casa não temos papéis sempre do mesmo tamanho, do mesmo formato, da mesma cor. As diferenças por aqui não são suprimidas, não há foco para resultados previsíveis. Este espaço pode se tornar um território privilegiado da expressão criativa.

Além de outra qualidade de espaço e de materiais, Luciana Ostetto (2011) aponta que sentidos e práticas possíveis com a arte exigem outra qualidade de tempo. $\mathrm{O}$ isolamento social forjou outra temporalidade. Neste momento, como diria Ostetto, estamos entregues ao processo. Em algumas casas da grande cidade, o tempo segue pausado para as crianças em situação de confinamento. Supervisionadas por algum adulto, visto que o ritmo do trabalho parou por pouco tempo, não permitindo um isolamento prolongado. Este tempo suspenso pode provocar o desejo que faz mover a busca pela experimentação e experiência, pelo pensar e fazer. Alguns têm tempo junto para viver em casa aventuras à procura de poesia, visto que, aquele tem- 
po que passava apressado com o tic-tac-tic-tac, que roubava o momento da entrega e impedia a construção do olhar sensível, está diferente.

O espaço tornou-se ainda mais íntimo e o tempo se alongou para as crianças. Os ritmos infantis estão sendo direcionados apenas pela família, uma vez que não há vivências com adultos fora do núcleo familiar durante o isolamento físico. E pode ser que permaneça assim por mais um longo período. Marcada por uma pandemia está a infância das crianças em situação de confinamento. Distantes dos espaços públicos, dos parquinhos e das praças, mas não indiferentes. Elas pertencem ao mundo, ainda que isoladas em seus espaços familiares com possibilidades limitadas.

\section{NA PAUSA, O ESPAÇO-TEMPO PARA VIVER A INFÂNCIA}

Estávamos todos, uns mais outros menos, enredados nos fazeres de uma vida metrificada, aprisionada em tempos, espaços demarcados nos quais transitamos com objetivos práticos e produtivos. Nessa lógica que nos enclausura, a sensibilidade e a criação ficam espremidas entre uma ocupação e outra. Nessa vida metrificada, a comunicação virtual adentra cada vez mais. Com a suspensão das atividades cotidianas nas formas como as tínhamos, a princípio, parecia que a virtualidade das experiências seria predominante. Talvez venha sendo, para os adultos.

Para as crianças não há vida virtual que dê conta de sua energia, de sua curiosidade e de sua possibilidade criativa. Nos espaços reclusos das casas e apartamentos elas transitam para criar o seu mundo próprio, pois, como registra Benjamin, "as crianças formam o seu próprio mundo de coisas, um pequeno mundo inserido no grande" (2007, p. 58). E formando seus mundos próprios as crianças vêm vivendo o confinamento desses tempos, revertendo aquilo que seria um aprisionamento em experiências outras na casa que virou mundo.

Fazer da casa mundo é uma arte de quem enxerga o que 
o adulto já não vê, de quem não olha as coisas com o entendimento do mundo adulto, logo, tem a possibilidade de atribuir outras significações às coisas, libertando-as para novas miragens.

Libertar e ressignificar as coisas podem se revelar no acampamento em que os livros se tornam cabana. Os livros são tão seus e com eles tem tamanha intimidade que pode submetê-los a novos usos, trazê-los para outras fantasias e depois resgatá-los para acessar suas histórias.

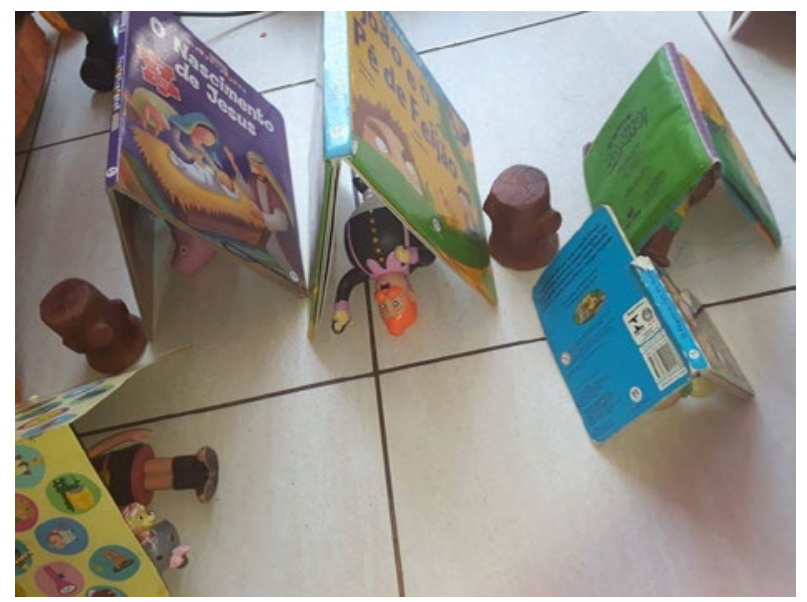

Figura 03

Fonte: arquivo pessoal de Simone Kluser cedida para esse trabalho (maio/2020)

O acampamento de livros-cabanas expressa a liberdade de criar que a infância contém e sobre isso Benjamin registra:

Nesses produtos residuais elas reconhecem o rosto que o mundo das coisas volta exatamente para elas, e somente para elas. Neles, estão menos empenhadas em reproduzir as obras dos adultos do que em estabelecer uma relação nova e incoerente entre esses restos e materiais residuais (BENJAMIN, 2007, p. 58). 
A pequena de quatro anos captura nos resíduos outros sentidos e reconhece o que esses lhe apresentam de possibilidades e experiências. Não importam os usos que os adultos deem aos materiais, importa construir através deles seu mundo próprio que se revela impregnado de experiências anteriores, porém orientados pelas suas experimentações. É o que ela nos apresenta quando, em outro momento de brincadeiras, organiza os pregadores de roupa em duas filas e a frente de cada fila se encontra um círculo de massinha. Observando sua brincadeira podemos compreender que as filas separam meninos e meninas que se revezam para pular no bambolê de massinha. Há uma experiência anterior que se expressa através de um mundo no qual os objetos, resíduos do mundo adulto, assumem outras possibilidades e encarnam as crianças que povoam sua vida pré-confinamento. Através da brincadeira, a menina se liberta do espaço/tempo do apartamento e se encontra com os pares na rememoração das atividades dirigidas que agora se tornam brincadeira, logo, se tornam a própria vida acontecendo, agora.

Retomamos Albano (2018) para pensar como, durante a crise provocada pela Covid-19 e seu consequente confinamento, as casas e apartamentos se tornam quintais. Quintais nos quais não se encontram os resíduos e a vida que a natureza nos possibilita, mas quintais repletos das miudezas que dão materialidade a sonhos, viagens, vidas, relações, alegrias, temores, mundos. Quintais que oferecem elementos para a criação e a expressão da criança na combinação e recombinação de diferentes materiais empregando-Ihes novos usos e Ihes designando outros significados.

Eisner (2008), aponta que as formas de pensar inerentes a arte, são essenciais para as experiências de aprendizagem e criação. Segundo o autor, o desenvolvimento de ideias, sensações, habilidades e imaginação que são necessários para a criação de um trabalho de boas proporções, bem realizado e criativo importam para todas as áreas de realização (2008, p.9). O autor se manifesta sobre a educação e a produção humana em geral e nos leva a associar essas formas de pensar e criar 
na infância ao brincar. Compreendemos que há uma profunda relação entre a brincadeira e arte como criação, experiência e forma de expressar o mundo.

Para Moura (2009, p. 81), a brincadeira congrega múltiplas linguagens, inclusive as artísticas, sendo a expressão de conhecimentos sociais e culturais. A brincadeira possibilita a criança a "exercer seu potencial imaginativo e criativo", pois através dela, a criança conecta-se aos próprios sentimentos e dá forma à imaginação. No sentido que discorre a autora, é possível afirmar que para a criança arte e vida são a mesma coisa.

\section{CONSIDERAÇÕES FINAIS}

Compartilhamos fragmentos dos encontros com as crianças em suas linguagens criativas. Um fazer muitas vezes inusitado, que esgarça a nossa compreensão metrificada do viver. Talvez, as crianças sejam nossas lentes de aumento, para ver o que antes não víamos.

Ao transver o olhar aprendemos com seus 'exercícios de ser criança' (BARROS, 2008). Seguimos com elas, experimentando trajetos insuspeitos, em que seus corpos, vozes e gestualidades nos permitem sentir a amplidão desse espaço-tempo em que vivemos o confinamento. E, o que pode nos conectar? Arte e infância.

Manoel de Barros (2008) afirma que a criança erra na gramática, mas acerta na poesia. É isso, buscamos a poesia. Encontramos nas linguagens das crianças um viver poético, sem grandes pretensões, mas que afirmam outras lógicas.

A brincadeira, arte e vida que se afirmam quando a realidade fora do quintal/casa não se encontra tão atrativa, é também para os adultos uma possibilidade de reviver, reinventar-se, reencontrar-se com a criança que um dia o habitou e ainda hoje o constitui. Em tempos de fragilidade humana, a criança faz justiça à experiência sensível e nos ensina como transformar os dias de angústia e tristeza em respostas estéticas transformadas em linguagem, permitindo reinventar, assim, a própria noção de humanidade. 


\section{REFERÊNCIAS}

ALBANO, Ana Angélica. Agora eu era o herói: imaginação e expressão artística na primeira infância. Revista Digital do LAV. vol. 11, n. 2, p. 09 - 19. Santa Maria, 2018.

BARROS, Manoel de. Memórias inventadas. A infância. São Paulo: Planeta, 2008.

BARROS, Manoel de. Eu sou o rascunho de um sonho. In: MÜLLER, Adalberto (org.) Manoel de Barros. Rio de Janeiro: Beco do Azougue, 2010.

BENJAMIN, Walter. Obras Escolhidas: magia e técnica, arte e política. São Paulo: Editora Brasiliense, 1994.

BENJAMIN, Walter. Reflexões sobre a criança, o brinquedo e a educação. São Paulo: Editora 34, 2007.

DELORY-MOMBERGER, Christine. Abordagens metodológicas na pesquisa biográfica. Revista Brasileira de Educação. v. 17, n. 51, p. 523-536, 2012.

EISNER, Elliot. O que pode a educação aprender das artes sobre a prática da educação? Currículo sem Fronteiras. v. 8, n. 2, p. 5-17, 2008. Disponível em: http://www.curriculosemfronteiras. org/

HOLM, Anne Marie. Eco-arte com crianças. São Paulo: AV Form, 2015.

MOURA, Maria Teresa J. A brincadeira como encontro de todas as artes. In: CORSINO, Patrícia. Educação Infantil: cotidiano e políticas. Campinas: Autores Associados, 2009.

OSTETTO, Luciana. Educação infantil e arte: sentidos e práticas possíveis. Cadernos de Formação da UNIVESP. São Paulo: Cultura Acadêmica, 2011. 
PASSEGGI, Maria da Conceição et. al. (orgs.). Pesquisa auto (biográfica) em educação: infâncias e adolescências em espaços escolares e não-escolares. Natal, RN: EDUFRN, 2018. 